RESENDE, G.M.; YURI, J.E.; MOTA, J.H.; SOUZA, R.J.; FREITAS, S.A.C.; RODRIGUES JUNIOR, J.C. Efeitos de tipos de bandejas e idade de transplantio de mudas sobre o desenvolvimento e produtividade de alface americana. Horticultura Brasileira, Brasília, v. 21, n. 3, p. 558-563, julho-setembro 2003.

\title{
Efeitos de tipos de bandejas e idade de transplantio de mudas sobre o desenvolvimento e produtividade da alface americana
}

\author{
Geraldo M. de Resende'; Jony E. Yuri²; José H. Mota²; Rovilson J. de Souza ${ }^{2}$; Silvio A.C. de Freitas ${ }^{3}$; \\ Juarez C. Rodrigues Junior ${ }^{3}$ \\ ${ }^{1}$ Embrapa Semi-Árido, C. Postal 23, 56300-000 Petrolina-PE; ${ }^{2}$ UFLA, C. Postal 037, 37200-000 Lavras-MG; ${ }^{3}$ REFRICON, Rod. Regis \\ Bittencourt s/n km 294, 06850-000 Itapecerica da Serra-SP; E-mail: gmilanez@ufla.br
}

\section{RESUMO}

Avaliou-se a influência de tipos de bandeja e idade de transplantio das mudas de alface (Lactuca sativa L.) tipo americana em ensaio, realizado de março a junho de 2002 no município de Três Pontas, MG. Utilizou-se o delineamento experimental em blocos ao acaso em esquema fatorial $3 \times 5$, compreendendo três tipos de bandejas (128; 200 e 288 células), cinco idades de transplantio $(22 ; 26 ; 30 ; 34$ e 38 dias após a semeadura) e 3 repetições. Mudas produzidas em bandejas de poliestireno expandido com 128 células e transplantadas com 38 dias de idade apresentaram maior massa fresca e seca, número de folhas e altura de plantas. A maior produtividade comercial foi obtida com as mudas produzidas em bandejas de 128 células, seguida da bandeja com 200 células, sendo o pior desempenho apresentado pelas mudas produzidas em bandejas com 288 células. A idade de transplantio das mudas variou em função do tipo de bandeja utilizado, podendo as mudas serem transplantadas de 22-38 dias da semeadura quando são utilizadas as bandejas com 128 e 200 células, com preferência para os períodos menores (22-30 dias). Para a bandeja com 288 células, as mudas devem ser transplantadas mais tardiamente, aos 38 dias da semeadura.

Palavras-chave: Lactuca sativa L., tipos de recipientes, crescimento, rendimento.

\section{ABSTRACT}

Effect of tray types and age of seedling on the development and yield of the crisphead lettuce

This study was carried out from March to July, 2002 at Três Pontas, Brazil, to evaluate the influence of tray types and transplanting age of seedlings over the development of crisphead lettuce (Lactuca sativa L.). Three types of tray (128; 200, and 288 cells) and five transplanting ages (22;26;30; 34 and 38 days after the sowing) were evaluated in a randomized complete block experimental design ( $3 \times 5$ factorial), with three replications. The 128 cells tray and the transplantation at 38 days after sowing date showed the highest fresh mass, driest weight, highest leaf number and highest plant height. The highest commercial yield was obtained with 128 cells tray, followed by the one with 200 cells. The lowest yield was obtained with the 288 cells tray. The transplanting age varied from 22 to 38 days after sowing date depending on the use of the 128 or 200 cells tray, with preference for the smaller periods ( 22 to 30 days). Using the tray with 288 cells, the seedlings should be transplanted at 38 days after sowing date.

Keywords: Lactuca sativa L., recipients type, growth.

(Recebido para publicação em 09 de outubro de 2002 e aceito em 18 de junho de 2003)

A cultura da alface (Lactuca sativa .) é largamente difundida no Brasil, sendo considerada a hortaliça folhosa mais consumida no país, destacando-se como cultura de grande importância econômica e alimentar. Atualmente, com o aumento do número de redes de lanchonetes do tipo "fast-food", vem se sobressaindo o grupo de alface denominado "crisphead lettuce" ou tipo "americana". Segundo dados da a CEAGESP (2001), do total de $25.558 \mathrm{t}$ da alface comercializada em 2001, $29,6 \%$ foi do tipo americana.

A alface do tipo americana se diferencia dos demais grupos, por apresentar folhas externas de coloração verdeescura, folhas internas de coloração amarela ou branca, imbricadas, semelhantes ao repolho e crocantes, apresentar maior vida pós-colheita, possibilitando o transporte a longas distâncias
(Decoteau et al., 1995), e elevados teores de vitaminas e sais minerais, além de baixo teor calórico (Katayama, 1993).

Na produção de mudas de alface era comum, até meados da década de 80 , o transplantio de mudas formadas em canteiros. Com a introdução em 1984, do sistema de bandejas de isopor, ocorreu uma modernização no sistema de produção de mudas e, consequentemente, melhoria da qualidade das mudas de hortaliças (Minami, 1995). A utilização de bandejas para a produção de mudas aumenta o rendimento operacional; reduz quantidade de sementes; uniformiza as mudas, facilita o manuseio no campo, melhora o controle fitossanitário e permite a colheita mais precoce (Borne, 1999; Filgueira, 2000).

Para a produção de mudas de alface são recomendadas bandejas com 200 células (Goto, 1998), até 288 células (Filgueira, 2000). Cati (1997) recomenda as bandejas de 200 e 288 células com transplante em períodos variáveis de 21 a 28 dias. Para as condições de Campo Grande, a cultivar Verônica, transplantada aos 30 dias da semeadura, produziu massas frescas de 1,62;0,98 e 0,76 g.planta ${ }^{-1}$ respectivamente, para as bandejas de 128, 200 e 288 células (Cesconetto et al., 2001).

Existem no mercado diversos tipos de bandejas de poliestireno expandido, apresentando variações de 128; 200; 242; 284 e 288 células. Na prática, entre os produtores de alface americana, tem se observado uma preferência por bandejas de 200 células, embora existam produtores que utilizam as de 128 ou 288 células, entretanto, as utilizando sem base cientifica. Outro fator importante na formação de mudas é a grande 
variação entre os produtores com relação à idade de transplantio das mudas, verificando-se transplantios desde 17 dias até 35 dias após a semeadura. Yuri et al. (2002), informa ser este período de 20 a 30 dias, dependendo da época do ano.

Diante destas constatações, das controvérsias e da carência de estudos científicos, o presente trabalho teve como objetivo avaliar diferentes tipos de bandejas e idades de mudas sobre o desenvolvimento e produtividade da alface americana.

\section{MATERIAL E MÉTODOS}

O experimento foi conduzido no município de Três Pontas, à latitude de $21^{\circ} 22^{\prime} 00$ ' $\mathrm{S}$, longitude de $45^{\circ} 30^{\prime} 45^{\prime \prime} \mathrm{W}$ e altitude de $855 \mathrm{~m}$. O clima da região é do tipo Cwa com características de Cwb, apresentando duas estações definidas: seca (abril a setembro) e chuvosa (outubro a março), segundo a classificação climática de Köppen. O tipo de solo predominante na área é classificado como Latossolo Vermelho Distrófico (LVd.).

O delineamento utilizado foi de blocos casualizados, em esquema fatorial 3 x 5, sendo 3 tipos de bandejas de poliestireno expandido $(128 ; 200$ e 288 células) e 5 idades de transplantio (22; 26; 30; 34 e 38 dias após a semeadura), com 3 repetições. Produziu-se as mudas de alface cultivar Raider utilizando-se substrato comercial (Plantmax) para o preenchimento das células e semeou-se 2 a 3 sementes por célula. No desbaste das mudas deixou-se uma planta (mais vigorosa) por célula. As semeaduras foram realizadas entre os dias 19/03 e 04/ $04 / 2002$, em intervalos de 4 dias e o transplantio efetuado no dia 26/04/2002. As bandejas permaneceram em viveiro de mudas, recebendo os tratos culturais, que consistiam de irrigações diárias e pulverizações regulares com produtos à base de mancozeb e piretróides, até o momento de transplante.

A área experimental foi demarcada nos canteiros centrais da área de produção, e as parcelas experimentais constituídas de quatro linhas de 2,1 m de comprimento, espaçadas a cada $0,35 \mathrm{~m}$ e $0,30 \mathrm{~m}$ entre plantas, sendo consideradas como área útil as duas linhas cen- trais, eliminando-se duas plantas em cada extremidade.

Essa área foi previamente corrigida com calcário dolomítico, elevando a saturação por base para $70 \%$ de acordo com as recomendações de Raij et al. (1996), e adubada com $65 \mathrm{~kg}$ de N.ha ${ }^{-1}$, $600 \mathrm{~kg}$ de $\mathrm{P}_{2} \mathrm{O}_{5} \cdot \mathrm{ha}^{-1}$ e $256 \mathrm{~kg}$ de $\mathrm{K}_{2} \mathrm{O} \cdot \mathrm{ha}^{-1}$, utilizando como fontes o adubo formulado 04-30-6 e superfosfato simples. Após os adubos serem incorporados ao solo, instalou-se em cada canteiro duas linhas de tubo gotejador, com emissores espaçados a cada $30 \mathrm{~cm}$ e com vazão de $1,5 \mathrm{~L} \cdot \mathrm{h}^{-1}$. Foi instalada, em toda a área, uma estrutura de proteção, constituída de túneis altos com $2 \mathrm{~m}$ de altura, cobrindo dois canteiros por túnel, constituído de tubos de ferro galvanizados, coberta com filme plástico transparente de baixa densidade, aditivado com anti-UV, de 100 micras de espessura, sendo os canteiros revestidos com filme plástico preto "mulching", de $4 \mathrm{~m}$ de largura e 35 micras de espessura.

Após o transplantio, irrigou-se a área por aspersão, diariamente, durante 7 dias, até o pegamento uniforme das plantas. Posteriormente a irrigação foi realizada por gotejamento. Juntamente com a irrigação, realizaram-se as adubações de cobertura (fertirrigação) diariamente, totalizando $40 \mathrm{~kg}$ de N.ha ${ }^{-1} \mathrm{e}$ $85 \mathrm{~kg}$ de $\mathrm{K}_{2} \mathrm{O}$ ha $^{-1}$, utilizando-se como fontes uréia e cloreto de potássio.

Quanto ao controle fitossanitário, adotou-se o método padrão utilizado pelo produtor, com pulverizações semanais com produtos à base de oxicloreto de cobre, iprodione, procimidone e piretróides.

As avaliações foram realizadas em duas etapas: por ocasião do transplantio, quando se retirou aleatoriamente três plantas por parcela e se avaliou a massa fresca e seca, número de folhas e altura de planta; a segunda avaliação foi em campo por ocasião da colheita (22/06/ 2002), onde avaliou-se produtividade total e comercial (g/planta), produtividade comercial ajustada ( $\mathrm{t} / \mathrm{ha})$, circunferência da cabeça comercial e comprimento do caule $(\mathrm{cm})$. Para produtividade comercial, foram pesadas somente as cabeças comerciais, retirando-se as folhas externas. A produtividade comercial ajustada ( $t / h a)$ foi feita extrapolando-se os resultados de produtividade comercial (g/planta) para uma população de 60.000 plantas.ha ${ }^{-1}$ obtendo-se a produtividade comercial em toneladas e subtraindo-se o custo total da muda em reais transformado para $\mathrm{t} / \mathrm{ha}$. Para o cálculo do custo de formação de mudas, efetuou-se a soma entre as despesas proveniente da aquisição de bandejas e o gasto com substrato. Quanto às bandejas, pela possibilidade de reutilização, que de acordo com Filgueira (2000), pode ser superior a 20 vezes, estabeleceu-se como critério a divisão do custo da bandeja por 20 . O custo total da muda foi expresso em reais e posteriormente dividido pelo seu valor em função do preço recebido por $\mathrm{kg}$ do produto comercial, que em julho de 2002 situou-se em R $\$ 0,49$, verificando-se também a quantidade necessária do produto em toneladas/ha para pagar o custo de cada tipo de muda avaliada.

Os dados foram submetidos à análise de variância, seguindo esquema sugerido por Pimentel Gomes (1990), sendo as médias comparadas pelo teste de Tukey, ao nível de 5\% de probabilidade.

\section{RESULTADOS E DISCUSSÃO}

Para a produção de mudas em estufa observou-se efeito significativo da interação entre o tipo de bandeja e a idade das mudas para todas as características avaliadas. Pelo desdobramento da interação verificou-se para a bandeja com 128 células que a maior massa fresca e seca, número de folhas e altura de plantas foi alcançada quando o transplantio foi realizado com 38 dias de idade. Resultados similares foram constatados para as bandejas de $200 \mathrm{e}$ 288 células, à exceção da massa seca para a bandeja de 288 células, que não mostrou diferenças significativas quando as mudas foram transplantadas com 34 dias de idade. No entanto, salientase que os valores para todas as características avaliadas foram sempre superiores para a bandeja com 128 células, seguidas pelas bandejas de 200 e 288 células, em função da maior quantidade de nutrientes disponível para este tipo de bandeja, permitindo um maior desenvolvimento da muda. Estes resultados 
Tabela 1. Massa fresca e seca, número de folhas e altura de planta de alface americana em função dos tipos de bandejas e idades de transplantio. Três Pontas, UFLA, 2002.

\begin{tabular}{|c|c|c|c|c|c|}
\hline \multirow[b]{2}{*}{ Bandejas* } & \multirow[b]{2}{*}{ Idades (dias) } & \multicolumn{4}{|c|}{ Características avaliadas } \\
\hline & & $\begin{array}{c}\text { Massa fresca } \\
\text { (g) }\end{array}$ & Massa seca $(g)$ & $\begin{array}{l}\text { Número de } \\
\text { folhas }\end{array}$ & $\begin{array}{l}\text { Altura de planta } \\
\text { (cm) }\end{array}$ \\
\hline \multirow{5}{*}{128} & 22 & $1,64 \mathrm{~d}$ & $0,08 d$ & $5,0 \mathrm{~b}$ & $7,59 \mathrm{~d}$ \\
\hline & 26 & $2,95 \mathrm{c}$ & $0,15 c$ & $5,3 b$ & $8,87 \mathrm{c}$ \\
\hline & 30 & $3,50 \mathrm{c}$ & $0,16 \mathrm{c}$ & $5,4 \mathrm{~b}$ & $8,07 \mathrm{~cd}$ \\
\hline & 34 & $5,78 \mathrm{~b}$ & $0,29 b$ & $5,1 \mathrm{~b}$ & $11,59 \mathrm{~b}$ \\
\hline & 38 & $10,72 \mathrm{a}$ & $0,54 a$ & $6,4 a$ & 13,59 a \\
\hline \multirow[t]{3}{*}{ Médias } & & $4,92 \mathrm{~A}$ & $0,25 \mathrm{~A}$ & $5,46 \mathrm{~A}$ & $9,94 \mathrm{~A}$ \\
\hline & 22 & $1,26 \mathrm{~d}$ & $0,07 \mathrm{~d}$ & $4,1 \mathrm{~d}$ & $6,69 \mathrm{c}$ \\
\hline & 26 & $2,25 \mathrm{c}$ & $0,10 \mathrm{~cd}$ & $4,7 \mathrm{bc}$ & $8,23 \mathrm{~b}$ \\
\hline \multirow[t]{3}{*}{200} & 30 & $2,23 \mathrm{c}$ & $0,11 \mathrm{c}$ & $4,6 \mathrm{c}$ & $7,54 \mathrm{~b}$ \\
\hline & 34 & $3,32 \mathrm{~b}$ & $0,16 \mathrm{~b}$ & $5,2 a b$ & $8,32 \mathrm{~b}$ \\
\hline & 38 & $5,15 \mathrm{a}$ & $0,25 \mathrm{a}$ & $5,3 a$ & $11,13 a$ \\
\hline \multirow[t]{3}{*}{ Médias } & & $2,84 \mathrm{~B}$ & $0,14 \mathrm{~B}$ & $4,82 \mathrm{~B}$ & $8,38 \mathrm{~B}$ \\
\hline & 22 & $1,25 \mathrm{c}$ & $0,06 \mathrm{~b}$ & $4,0 \mathrm{c}$ & $6,65 \mathrm{c}$ \\
\hline & 26 & $1,35 \mathrm{c}$ & $0,07 \mathrm{~b}$ & $4,5 a b$ & $6,67 \mathrm{c}$ \\
\hline \multirow[t]{3}{*}{288} & 30 & $1,76 \mathrm{c}$ & $0,09 \mathrm{~b}$ & 4,2 bc & $7,08 \mathrm{c}$ \\
\hline & 34 & $2,67 \mathrm{~b}$ & $0,14 a$ & $4,2 \mathrm{bc}$ & $9,65 \mathrm{~b}$ \\
\hline & 38 & $3,71 \mathrm{a}$ & $0,17 \mathrm{a}$ & $5,0 \mathrm{a}$ & $11,06 \mathrm{a}$ \\
\hline Médias & & $2,15 \mathrm{C}$ & $0,11 \mathrm{C}$ & $4,39 \mathrm{C}$ & $8,22 \mathrm{~B}$ \\
\hline C.V. (\%) & & 10,86 & 10,00 & 4,39 & 4,15 \\
\hline
\end{tabular}

Médias seguidas de mesma letra minúscula e maiúsculas nas colunas não diferem entre si a 5\% de probabilidade pelo teste de Tukey.

* Número de células por bandeja

podem ser facilmente visualizados pela média obtida para as diferentes características em função das idades das mudas (Tabela 1).

Comparando os resultados obtidos pelas mudas com 30 dias para massa fresca $\left(3,50 ; 2,23\right.$ e 1,76 g.planta ${ }^{-1}$ para as bandejas de 128; 200 e 288, respectivamente), verifica-se valores superiores aos obtidos por Cesconetto et al. (2001) que, nas condições de Campo Grande, com a alface cultivar Verônica, aos 30 dias obtiveram massas frescas de 1,62; 0,98 e 0,76 g.planta $^{-1}$, para as bandejas de 128; 200 e 288 células, respectivamente. Ao contrário, Vitória et al. (2002), relatam um maior ganho de massa fresca e seca independentemente das cultivares utilizadas, para bandejas de 450 células, apesar de não terem encontrado diferenças significativas entre as bandejas com 200 e 288 células.

Em relação ao número de folhas, para o transplantio aos 30 dias de idade para bandejas de 200 e 288 células verificou-se 4,6 e 4,2 folhas.planta-1 ${ }^{-1}$, valores estes superiores aos registrados por Vitória et al. (2002), que alcançaram 3,3 e 4,0 folhas.planta ${ }^{-1}$ para a cultivar Lucy Brown, na mesma idade de muda.

Pelos resultados apresentados em termos de produção de mudas pode-se inferir, em função das diferentes características analisadas, que a bandeja que proporciona a melhor muda é a com 128 células, seguidas das bandejas com 200 e 288 células e que a idade das mudas mais recomendável para transplantio deve ser de 38 dias. Neste contexto, estes resultados concordam em parte com os obtidos por Cesconeto et al. (2001), que verificaram que mudas produzidas com 30 dias de idade apresentam melhor desempenho em bandejas de 128 e 200 células quando comparadas a bandejas com 288 células. Assim como alicerça a indicação de Goto (1998) e contradiz a recomendação de Filgueira (2000) de utilização de bandejas de 288 células. Todavia, torna-se necessário verificar o retorno em termos de produtividade comercial de cabeça e os custos de produção das mudas, para se poder afirmar estes resultados com certeza.

Nas avaliações de campo por ocasião da colheita observou-se interação entre os tipos de bandeja e a idade de transplantio de mudas, apenas nas características peso total e comercial, enquanto que para as características comprimento de caule e circunferência da cabeça comercial, houve efeito significativo independentemente dos fatores estudados.

No desdobramento da interação, para a produtividade total, nota-se que não ocorreram diferenças significativas entre as diferentes idades de transplantio das mudas para as bandejas de 128 e 200 células. Para a bandeja de 288 células observou-se maior produtividade para as mudas transplantadas aos 38 e 34 
Tabela 2. Produtividade total e comercial de alface americana em função de diferentes idades das mudas e tipos de bandejas. Três Pontas, UFLA, 2002.

\begin{tabular}{lcccccc}
\hline \multirow{2}{*}{$\begin{array}{c}\text { Idade das } \\
\text { mudas }\end{array}$} & \multicolumn{5}{c}{ Produtividade (g.planta-1) } \\
\cline { 2 - 7 } & $\mathbf{1 2 8}^{*}$ & $\mathbf{2 0 0}^{*}$ & $\mathbf{2 8 8}^{*}$ & $\mathbf{1 2 8}^{*}$ & $\mathbf{2 0 0}^{*}$ & $\mathbf{2 8 8}^{*}$ \\
\hline 22 dias & $815,0 \mathrm{a}$ & $752,5 \mathrm{a}$ & $673,3 \mathrm{~b}$ & $523,3 \mathrm{a}$ & $436,7 \mathrm{a}$ & $359,4 \mathrm{c}$ \\
26 dias & $781,7 \mathrm{a}$ & $812,2 \mathrm{a}$ & $710,1 \mathrm{~b}$ & $490,8 \mathrm{a}$ & $456,1 \mathrm{a}$ & $384,9 \mathrm{bc}$ \\
30 dias & $780,5 \mathrm{a}$ & $753,4 \mathrm{a}$ & $741,6 \mathrm{~b}$ & $482,7 \mathrm{a}$ & $424,1 \mathrm{a}$ & $432,7 \mathrm{~b}$ \\
34 dias & $785,8 \mathrm{a}$ & $756,6 \mathrm{a}$ & $766,7 \mathrm{ab}$ & $501,6 \mathrm{a}$ & $456,1 \mathrm{a}$ & $419,4 \mathrm{bc}$ \\
38 dias & $795,0 \mathrm{a}$ & $795,5 \mathrm{a}$ & $857,5 \mathrm{a}$ & $501,6 \mathrm{a}$ & $487,8 \mathrm{a}$ & $513,3 \mathrm{a}$ \\
Médias & $791,6 \mathrm{~A}$ & $774,1 \mathrm{AB}$ & $749,9 \mathrm{~B}$ & $500,1 \mathrm{~A}$ & $452,2 \mathrm{~B}$ & $421,9 \mathrm{C}$ \\
\hline CV (\%) & 5,52 & & 6,15 \\
\hline
\end{tabular}

Médias seguidas pelas mesmas letras minúsculas na coluna e maiúsculas nas linhas não diferem entre si ao nível de 5\% de probabilidade pelo teste de Tukey.

* Número de células por bandeja

dias, com 857,5 e 766,7 g.planta ${ }^{-1}$, respectivamente, sem diferirem entre si (Tabela 2).

Para a produtividade comercial, os resultados da interação foram semelhantes aos observados na produtividade total, não se verificando diferenças em termos de idade de mudas para as bandejas de 128 e 200 células, sendo a maior produtividade comercial (513,3 g.planta $\left.{ }^{-1}\right)$ nas bandejas de 288 células alcançada aos 38 dias de idade (Tabela 2).

Analisando-se as bandejas, verificase que a de 128 células foi a que apresentou o maior peso comercial, com 500,1 g.planta ${ }^{-1}$, sendo estatisticamente superior às bandejas de 200 e 288 células com 452,2 e 421,9 g. planta $^{-1}$ respectivamente (Tabela 2).

O comprimento de caule, uma característica importante na cultura da alface americana, principalmente quando é destinada à indústria de beneficiamento, deve ser bastante reduzido, proporcionando menores perdas durante o processamento. Neste ensaio, constatou-se uma diferença significativa entre os tipos de bandeja e idade de transplantio. A bandeja de 128 células apresentou comprimento maior, com 2,8 $\mathrm{cm}$, sendo estatisticamente diferenciado das outras duas que apresentaram 2,52 e $2,54 \mathrm{~cm}$, respectivamente, para 200 e 288 células, embora este comprimento não seja prejudicial ao processamento estando abaixo dos observados por Mota et al. (2002a) e Yuri (2000), que verificaram comprimentos de 4,4 e 3,3 cm em seus respectivos trabalhos. Para as idades de mudas para o transplantio, praticamente não se observou diferenças entre as mudas, verificando-se uma variação de 2,37 a 2,78 $\mathrm{cm}$; ocorrendo maior comprimento com 38 dias $(2,78 \mathrm{~cm})$.

Em relação à circunferência de cabeça comercial, não se observou diferença estatística significativa entre bandejas que oscilou entre 41,4 aa $42,3 \mathrm{~cm}$ e entre as idades de mudas que apresentaram uma variação de 41,6 a $42,5 \mathrm{~cm}$. No entanto, todos os tratamentos apresentaram valores adequados para a comercialização, com resultados superiores aos observados por Mota et al. (2002b), que para a mesma cultivar, obtiveram uma circunferência de cabeça de $38,7 \mathrm{~cm}$.

A tabela 3 mostra a produtividade comercial ajustada em função do custo da muda de cada tipo de bandeja. Para a bandeja com 128 células a produtividade comercial ajustada não mostrou diferenças significativas em função das diferentes idades das mudas. No entanto, observa-se maiores valores quando as mudas são transplantadas com as menores idades, o que sugere ser a quantidade de substrato suficiente para um bom desenvolvimento inicial das mudas em menor espaço de tempo e de uma maior exigência nutricional, com melhor resposta ao nível de campo.

A bandeja com 200 células, apresentou resultados similares a 128 células não havendo diferenças estatísticas entre as diferentes idades de transplantio.
Para a bandeja com 288 células verificou-se que a maior produtividade foi alcançada quando se transplantou as mudas com 38 dias de idade, seguida por 30, 34 e 26 dias, que não mostraram diferenças significativas entre si. $\mathrm{Na}$ comparação dos diferentes tipos de bandejas, em função das diferentes idades de mudas, verifica-se que a maior produtividade ajustada em função do preço da muda foi obtida pela bandeja com 128 células com 29,0 t/ha, seguida das bandejas com 200 e 288 células com 26,1 e 24,3 t/ha. Ao contrário, economicamente, a bandeja com 288 células proporcionou o menor custo das mudas por hectare (R\$139,50), seguida pelas bandejas de $200(\mathrm{R} \$ 212,23)$ e 128 células (R\$ 505,93), no entanto, não propiciou um maior retorno ao produtor em termos de produtividade comercial. Estes resultados em parte concordam com as recomendações de Goto (1999) de que a melhor forma de produção de mudas de alface é em bandejas de 200 células, e que bandejas com maior número de células poderão ser mais vantajosas economicamente, havendo, no entanto, prejuízos na produção final.

Os resultados obtidos nas diferentes características avaliadas em estufa e campo evidenciam ser a bandeja com 128 células a que promove o maior desenvolvimento e produtividade comercial da alface americana, seguida da bandeja com 200 células, sendo o pior desempenho apresentado pela bandeja com 288 células. A idade de transplantio 
Tabela 3. Produtividade comercial ajustada e custos de produção de mudas de alface americana em função de tipos de bandejas e idades das mudas. Três Pontas, UFLA, 2002.

\begin{tabular}{|c|c|c|c|c|c|c|}
\hline \multirow{2}{*}{ Bandejas/idades (dias) } & \multicolumn{5}{|c|}{128 células } & \multirow{2}{*}{ Média } \\
\hline & 22 & 26 & 30 & 34 & 38 & \\
\hline Prod. Comercial ajustada (t/ha) ${ }^{\star}$ & $30,4 a^{2}$ & $28,4 a$ & $25,8 a$ & 25,6 a & $25,4 a$ & \multirow{8}{*}{$29,0 \mathrm{~A}^{2}$} \\
\hline Valor produto $(\mathrm{R} \$ / \mathrm{kg})$ & 0,49 & 0,49 & 0,49 & 0,49 & 0,49 & \\
\hline$N^{\circ}$ bandeja/ha & 473 & 473 & 473 & 473 & 473 & \\
\hline Custo bandeja (R\$/ha) & 4,50 & 4,50 & 4,50 & 4,50 & 4,50 & \\
\hline Qtide substrato/ha (sc 25 kg) & 47 & 47 & 47 & 47 & 47 & \\
\hline Custo substrato $(\mathrm{R} \$ / \mathrm{sc})$ & 8,50 & 8,50 & 8,50 & 8,50 & 8,50 & \\
\hline Custo total R\$ (band. + sub.) & 505,93 & 505,93 & 505,93 & 505,93 & 505,93 & \\
\hline Custo (t/ha) $)^{1}$ & 1,032 & 1,032 & 1,032 & 1,032 & 1,032 & \\
\hline \multirow{2}{*}{ Bandejas/idades (dias) } & \multicolumn{5}{|c|}{200 células } & \multirow{2}{*}{ Média } \\
\hline & 22 & 26 & 30 & 34 & 38 & \\
\hline Prod. Comercial ajustada (t/ha) & $25,2 \mathrm{a}$ & $26,4 a$ & $24,4 a$ & $26,3 a$ & $28,3 \mathrm{a}$ & \multirow{8}{*}{$26,1 \mathrm{~B}$} \\
\hline Valor produto $(\mathrm{R} \$ / \mathrm{kg})$ & 0,49 & 0,49 & 0,49 & 0,49 & 0,49 & \\
\hline $\mathrm{N}^{\circ}$ bandeja/ha & 301 & 301 & 301 & 301 & 301 & \\
\hline Custo bandeja (R\$/ha) & 4,50 & 4,50 & 4,50 & 4,50 & 4,50 & \\
\hline Qtide substrato/ha (sc/25 kg) & 17 & 17 & 17 & 17 & 17 & \\
\hline Custo substrato $(\mathrm{R} \$ / \mathrm{sc})$ & 8,50 & 8,50 & 8,50 & 8,50 & 8,50 & \\
\hline Custo total $\mathrm{R} \$$ (band. + sub.) & 212,23 & 212,23 & 212,23 & 212,23 & 212,23 & \\
\hline Custo (t/ha) ${ }^{1}$ & 0,433 & 0,433 & 0,433 & 0,433 & 0,433 & \\
\hline \multirow{2}{*}{ Bandejas/idades (dias) } & \multicolumn{5}{|c|}{288 células } & \multirow{2}{*}{ Média } \\
\hline & 22 & 26 & 30 & 34 & 38 & \\
\hline Prod. Comercial ajustada (t/ha) & $20,6 \mathrm{c}$ & $22,1 \mathrm{bc}$ & $25,0 \mathrm{~b}$ & $24,2 \mathrm{bc}$ & $29,8 \mathrm{a}$ & \multirow{8}{*}{$24,3 \mathrm{C}$} \\
\hline Valor produto $(\mathrm{R} \$ / \mathrm{kg})$ & 0,49 & 0,49 & 0,49 & 0,49 & 0,49 & \\
\hline $\mathrm{N}^{\circ}$ bandeja/ha & 206 & 206 & 206 & 206 & 206 & \\
\hline Custo bandeja (R\$/ha) & 4,50 & 4,50 & 4,50 & 4,50 & 4,50 & \\
\hline Qtide substrato/ha $(\mathrm{sc} / 25 \mathrm{~kg}$ ) & 11 & 11 & 11 & 11 & 11 & \\
\hline Custo substrato $(\mathrm{R} \$ / \mathrm{sc})$ & 8,50 & 8,50 & 8,50 & 8,50 & 8,50 & \\
\hline Custo total R\$ (band. + sub.) & 139,85 & 139,85 & 139,85 & 139,85 & 139,85 & \\
\hline Custo (t/ha) ${ }^{1}$ & 0,285 & 0,285 & 0,285 & 0,285 & 0,285 & \\
\hline
\end{tabular}

* Produtividade comercial ajustada $(\mathrm{t} / \mathrm{ha})=$ produtividade comercial $(\mathrm{t} / \mathrm{ha})$ - custo total da muda $(\mathrm{t} / \mathrm{ha})$.

${ }^{1}$ Custo $(\mathrm{t} / \mathrm{ha})=$ custo total $(\mathrm{R} \$) /$ valor do produto $(\mathrm{R} \$ / \mathrm{kg})$.

${ }^{2}$ Médias seguidas pelas mesmas letras minúsculas nas linhas e maiúsculas nas colunas não diferem entre si ao nível de 5\% de probabilidade pelo teste de Tukey.

das mudas varia em função do tipo de bandeja utilizado. Assim as mudas podem ser transplantadas entre 22 e 38 dias utilizando-se bandejas com 128 e 200 células, com preferência para períodos menores de 22 a 30 dias em função da menor permanência na estufa e menor custo. Para a bandeja com 288 células as mudas devem ser transplantadas mais tardiamente aos 38 dias da semeadura. Salienta-se, no entanto, a necessidade de se realizarem pesquisas no período de verão, que apresenta condições de tem- peraturas bem distintas das ocorridas durante o presente experimento.

\section{LITERATURA CITADA}

BORNE, H.R. Produção de mudas de hortaliças. Guaíba: Agropecuária, 1999. 189 p.

CATI. Manual técnico das culturas. Campinas: CATI, Tomo II, 1997, 234 p. (CATI, Manual, 08). CESCONETTO, A.O.; LAURA, V.A.; FAVERO, S. Tamanho de bandeja para a produção de mudas de alface cv Verônica em Campo Grande-MS. Horticultura Brasileira, Brasília, v. 19, n. 2, Suplemento, 2001. 3 p. (CD-ROM).
CEAGESP. Conjuntura de produtos por agência. Boletim Mensal. São Paulo. jan./dez. 2001. DECOTEAU, D.R.; RANWALA, D.; McMAHON, M.J.; WILSON, S.B. The lettuce growing handbook: botany, field procedures, growing problems, and postharvest handling. Illinois: Oak Brook, 1995. 60 p.

FILGUEIRA, F.A.R. Novo manual de olericultura: agrotecnologia moderna na produção e comercialização de hortaliças. Viçosa: UFV, 2000. 402 p.

GOTO, R. A cultura da alface. In.: GOTO, R., TIVELLI, S.W. (org.). Produção de hortaliças em ambiente protegido: condições subtropicais. São Paulo, Fundação Editora da UNESP, 1998, p. 137-159. 
KATAYAMA, M. Nutrição e adubação de alface, chicória e almeirão. In: SIMPÓSIO SOBRE NUTRIÇÃO E ADUBAÇÃO DE HORTALIÇAS, 1990, Jaboticabal. Anais...Piracicaba: POTAFOS 1993. Cap. 4, p. 141-148.

MINAMI, K. Produção de mudas de alta qualidade em horticultura. São Paulo: T.A. Queiroz, 1995. $135 \mathrm{p}$.

MOTA, J.H.; YURI, J.E.; FREITAS, S.A.C.; RODRIGUES JUNIOR J.C.; RESENDE, G.M.; SOUZA, R.J. Comportamento de cultivares de alface americana quanto à queima dos bordos ("tip-burn") na região sul de Minas Gerais. Horticultura Brasileira, Brasília, v. 20, n. 2, Suplemento 2, 2002a. 4 p. (CD-ROM)
MOTA, J.H.; YURI, J.E.; FREITAS, S.A.C.; RODRIGUES JUNIOR J.C.; RESENDE, G.M.; SOUZA, R.J. Avaliação de cultivares de alface americana em Santana da Vargem, MG. Horticultura Brasileira, Brasília, v. 20, n. 2, Suplemento 2, 2002b. 4 p. (CD-ROM)

PIMENTEL GOMES, F. Curso de estatística experimental. 13. ed. São Paulo: Nobel, 1990. 468 p. RAIJ, B.; CANTARELLA, H.; QUAGGIO, J.A.; FURLANI, A.M.C. (eds). Recomendações de adubação e calagem para o Estado de São Paulo. 2. ed. Campinas: IAC, 1996. (IAC. Boletim 100).
VITÓRIA, D.P.; RIZZO, A.A.N.; VITÓRIA, E.S.S. Desenvolvimento de mudas de alface em quatro tipos de recipientes. Horticultura Brasileira, Brasília, v. 20, n. 2, Suplemento 2, 2002. 4 p. (CD-ROM).

YURI, J.E. Avaliação de cultivares de alface americana em duas épocas de plantio e dois locais do sul de Minas Gerais. Lavras: UFLA, 2000. 51 p. (Tese mestrado), UFLA, Lavras.

YURI J.E.; MOTA, J.H.; SOUZA, R.J.; RESENDE, G.M.; FREITAS, S.A.C.; RODRIGUES JUNIOR, J.C. Alface americana: Lavras: UFLA, 2002. 51 p. (UFLA, Textos Acadêmicos, 13). 